\title{
Heat Transfer Enhancement in a Backward-Facing Step with Heated Obstacle Using Nanofluid
}

\author{
L. Bouazizi \\ National Engineering School of Sfax, University of Sfax \\ BP W-3038, 1173 Sfax, Tunisia \\ Email: lot.bouazizi@yahoo.fr \\ Phone: +21697243771
}

\begin{abstract}
A numerical investigation was conducted to analyze the effect of the presence of a square obstacle placed behind the first primary recirculation zone on the flow field and heat transfer over a backward-facing step using copper-water nanofluid. Computations were performed over a range of Richardson number $R i$ from 0 to 2.85 and volume fraction of nanoparticles $\varphi$ from 0 to $15 \%$ at a fixed Reynolds number $R e=450$ and Prandtl number $\operatorname{Pr}=6.2$. A discussion about the buoyancy effect on the heat transfer exchanged between the horizontal walls of the channel as well as on the heat flux transferred from the obstacle to the flow for different $\varphi$. Results show that, the presence of heated square obstacle is effective in augmenting the heat transfer. In fact, in presence of the square obstacle, enhancements in the maximum values of the Nusselt number of $194 \%$ and $153 \%$ are obtained at the lower and the upper walls of the channel, respectively. Furthermore, the heat transfer reaches its maximum at the emplacement of the square cylinder. On the other hand, results show a marked improvement in heat transfer compared to the base fluid. This improvement is more pronounced for higher $R i$ and $\varphi$. Finally, the effect of the buoyancy forces is found less important on the heat transfer enhancements when $\mathrm{Ri}$ increases. This can be explained by the thermophoresis forces effect near the hot walls of the obstacle.
\end{abstract}

Keywords: heat transfer enhancement; thermal conductivity; $\mathrm{Cu}$-water nanofluid; backward-facing step; square obstacle

\section{NOMENCLATURE}

$\mathrm{C}_{\mathrm{p}} \quad$ specific heat at constant pressure $\left(\mathrm{kJ} \cdot \mathrm{kg}^{-1} \cdot \mathrm{K}^{-1}\right)$

$\mathrm{h}$ convection heat transfer coefficient $\left(\mathrm{W} \cdot \mathrm{m}^{-2} \cdot \mathrm{K}^{-1}\right)$

$\mathrm{H}$ downstream channel height $(\mathrm{m})$

$\mathrm{k}$ thermal conductivity $\left(\mathrm{W} \cdot \mathrm{m}^{-1} \cdot \mathrm{K}^{-1}\right)$

$\mathrm{L} \quad$ length of the channel $(\mathrm{m})$

$\mathrm{Lr}$ reattachment length, dimensionless

$\mathrm{Nu}$ Nusselt number

$\overline{\mathrm{Nu}}$ Time and space-average Nusselt number

$\langle\overline{\mathrm{Nu}}\rangle$ Global time and space-average Nusselt number

$\mathrm{P}$ dimensionless pressure

$\mathrm{p}$ pressure $\left(\mathrm{N} \cdot \mathrm{m}^{-2}\right)$ 


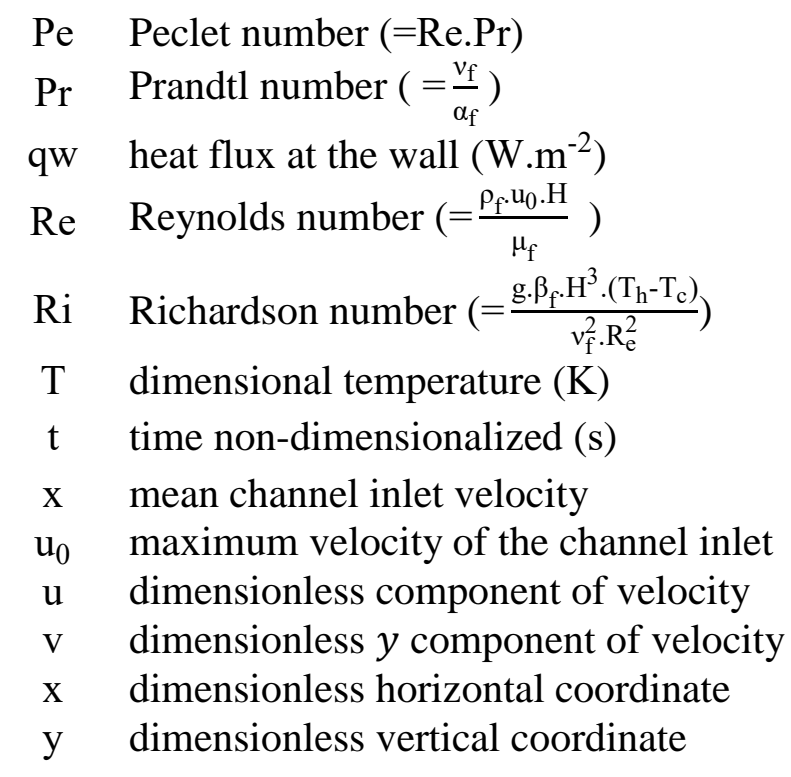

Greek symbols

$\alpha \quad$ thermal diffusivity $\left(\mathrm{m}^{2} \cdot \mathrm{s}^{-1}\right)$

$\beta \quad$ coefficient of thermal expansion $\left(\mathrm{K}^{-1}\right)$

$\phi \quad$ transport quantity

$\varphi$ nanoparticle volume fraction

$v \quad$ kinematic viscosity $\left(\mathrm{m}^{-2} \cdot \mathrm{s}^{-1}\right)$

$\mu \quad$ dynamic viscosity $\left(\mathrm{kg} \cdot \mathrm{m}^{-1} \cdot \mathrm{s}^{-1}\right)$

$\theta$ dimensionless temperature

$\rho \quad$ density $\left(\mathrm{kg} \cdot \mathrm{m}^{-3}\right)$

$\tau \quad$ time dimensionalized

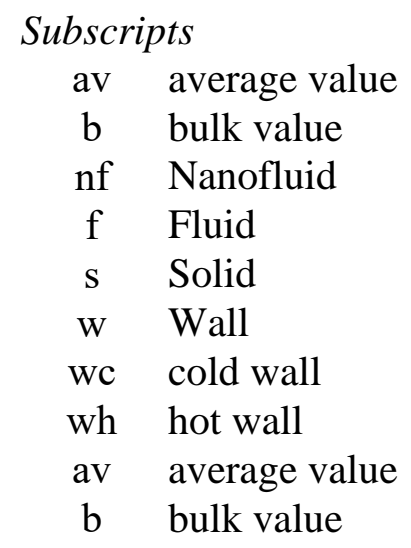

\section{INTRODUCTION}

It is well known that the study of backward-facing step flows is an important branch of fundamental fluid mechanics. A first study that treats flow and heat transfer using pure fluid was simulated by Armaly's et al. [1]. Then, several studies have been conducted in this area [2-6]. However, to the best of our knowledge, few research studies have tackled this area using nanofluids. This new class of fluids, composed of metal nanoparticles suspended in a base fluid, has recently appeared, due to their anomalous thermal conductivity enhancement. Many studies have been undertaken in the area of flow and 
heat transfer of nanofluids, showing that these new fluids have a remarkable power of heat exchange compared to conventional liquid [7-9]. This enhanced thermal behavior of nanofluids could provide a basis for an enormous innovation for heat transfer intensification, which is a major importance to a number of industrial sectors including transportation, power generation, heating, cooling, ventilation and air-conditioning. The first study that analyzed the flow of nanofluids on the flow pattern and its related heat transfer over a backward-facing step is that of Abu-Nada [10]. Their results, obtained in forced convection, show that nanoparticles with high thermal conductivity have more enhancement on the value of Nusselt number outside the recirculation zones. The effect of nanofluids flow on a mixed convection heat transfer over a 2D horizontal micro scale backward-facing step placed in a duct has been conducted numerically for different nanoparticles $\left(\mathrm{Al}_{2} \mathrm{O}_{3}, \mathrm{CuO}, \mathrm{SiO}_{2}\right.$ and $\left.\mathrm{ZnO}\right)$, whose, results show that the Nusselt number increases with the increase of the volume fraction and Reynolds number [11].

The compactness of new thermal systems leads the importance of finding effective means for enhancing heat transfer. Using baffles is one of an effective method for this purpose. It is well known that the flow of fluids past bluff bodies has been the subject of several researches, both experimental and theoretical. The motivation behind these studies was to understand the physical phenomenon that occurs behind the bluff body and find practical applications in industrial processes, such as aerodynamics, flow dividers in polymer processing applications, heat exchanger systems, cooling of electronic components, etc. A study of flow of nanofluids around a circular cylinder was performed to examine the effect of the nanoparticles volume fraction on the flow pattern and heat transfer characteristics. Results showed that the length of recirculation zone increases with the nanoparticles volume fraction and the Nusselt numbers was strengthened by the addition of nanoparticles to the base fluid [12]. The flow and heat transfer of nanofluids past a square cylinder in vertically upward flow have been simulated to examine the effect of the nanoparticles volume fraction on the overall flow coefficients such us the Strouhal number $(S t)$, the drag coefficient $(C d)$ and the lift coefficient $(\mathrm{Cl})$ [13]. A numerical study was conducted to simulate the steady laminar forced convection flow and heat transfer of $\mathrm{Al}_{2} \mathrm{O}_{3}$-water nanofluid around a square cylinder [14]. In a recent study about convection flow over BFS, it was revealed that a baffle mounted onto the upper wall increases considerably the magnitude of maximum Nusselt number at the stepped wall [15]. Likewise, the results of the study of the convection laminar flow over inclined backward-facing steps in a duct with a baffle mounted onto the upper wall show that although the baffle enhances the convection coefficient on the bottom wall [16]. A study was analyzed the heat transfer enhancement of 2D laminar and turbulent mixed convective flows adjacent to backward facing step with baffle installation onto the channel wall using different types of nanofluids. The aim is to study the effect of nanoparticles and the baffle on the heat transfer enhancement [17]. Another study was conducted to examine the effect of the rectangular cylinder on the laminar forced convection nanofluid flow and heat transfer over a backward-facing step [18].

The present research work was carried out to contribute to the existing knowledge of backward-facing step flow with a built in square obstacle using $\mathrm{Cu}$-water nanofluid. It is a numerical investigation on forced and mixed convection flow over a backward-facing step. The study is particularly focused on the effect of the presence of the square obstacle, as well as the effect of the buoyancy term (Richardson number) and the nanoparticles volume fraction on the flow pattern and its related heat transfer. Numerical simulations are performed out for Richardson number, $\mathrm{Ri}$, up to 2.85 and a volume fraction $\varphi$ of 
Copper nanoparticles from 0 to $15 \%$ at a fixed Reynolds number, $\mathrm{Re}=450$ and Prandtl number, $\operatorname{Pr}=6.2$.

\section{GOVERNING EQUATIONS}

Both of the flow geometry and the coordinate system are shown in Figure 1. The conservation equations describing the flow are time-dependent, two-dimensional NavierStokes and energy equations of incompressible nanofluid. The base fluid (water) and the nanoparticles $(\mathrm{Cu})$ are assumed to be in thermal equilibrium and all the physical properties of nanofluids (in Table 1) are assumed to be constant except for the variation of density in buoyancy term of momentum equation. The density variation is treated by the Boussinesq approximation. Thus, the dimensionless of the continuity, momentum and thermal energy equations governing the laminar flow over the backward-facing step can be written in the following conservative form of Eq. (1) to (4).

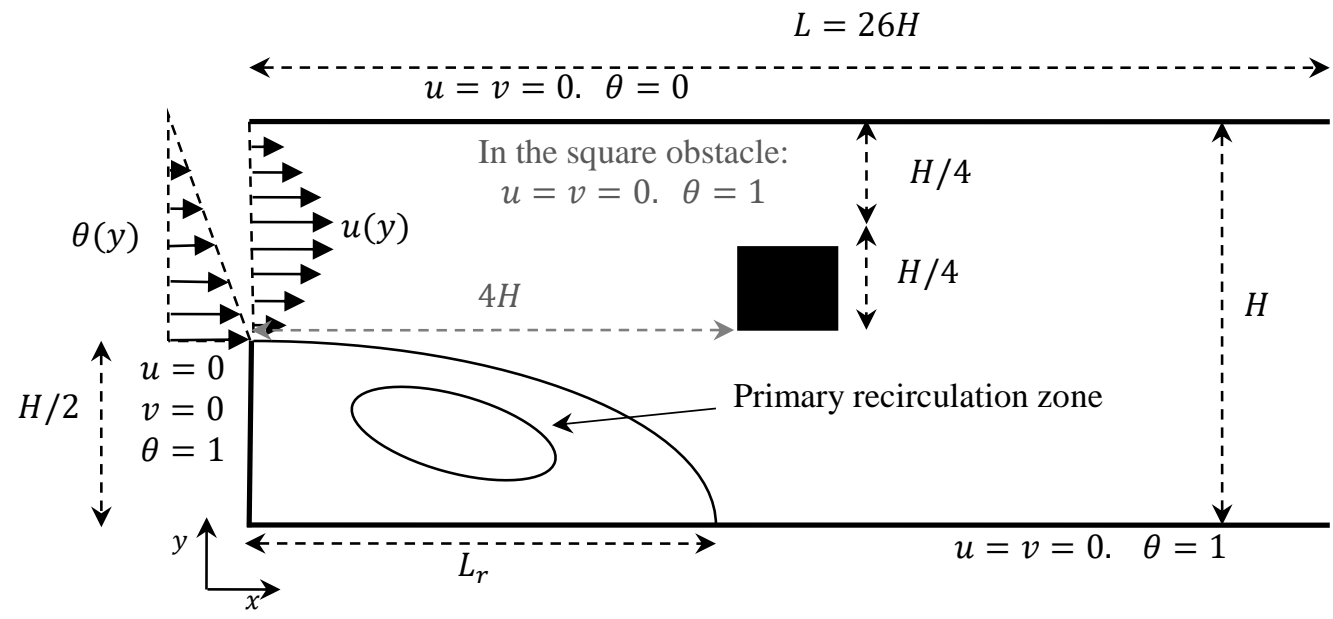

Figure 1. Configuration definition.

Table 1. Thermo-physical properties.

\begin{tabular}{lcc}
\hline Property & Fluid phase (Water) & $\mathrm{Cu}$ \\
\hline$C p(\mathrm{~J} / \mathrm{kg} \mathrm{K})$ & 4179 & 385 \\
$\rho\left(\mathrm{kg} / \mathrm{m}^{3}\right)$ & 997.1 & 8933 \\
$k\left(\mathrm{~W} / \mathrm{m} \mathrm{K}^{3}\right.$ & 0.613 & 400 \\
$\alpha \times 10^{7}\left(\mathrm{~m}^{2} / \mathrm{s}\right)$ & 1.47 & 1163.1 \\
\hline
\end{tabular}

$\operatorname{div}(\mathbf{V})=0$

$\frac{\partial u}{\partial \tau}+\operatorname{div}\left(\mathbf{J}_{\mathbf{u}}\right)=-\frac{\rho_{\mathrm{f}}}{\rho_{\mathrm{nf}}} \frac{\partial \mathrm{P}}{\partial \mathrm{x}}, \mathbf{J}_{\mathrm{u}}=\mathrm{u} \mathbf{V}-\frac{1}{\operatorname{Re}} \frac{\mu_{\mathrm{nf}}}{\mu_{\mathrm{f}}} \frac{\rho_{\mathrm{f}}}{\rho_{\mathrm{nf}}} \operatorname{grad}(\mathrm{u})$

$\frac{\partial \mathrm{v}}{\partial \tau}+\operatorname{div}\left(\mathbf{J}_{\mathbf{v}}\right)=-\frac{\rho_{\mathrm{f}}}{\rho_{\mathrm{nf}}} \frac{\partial \mathrm{P}}{\partial \mathrm{y}}+\frac{\varphi \rho_{\mathrm{s}} \beta_{\mathrm{s}}+(1-\varphi) \rho_{\mathrm{f}} \beta_{\mathrm{f}}}{\rho_{\mathrm{nf}} \beta_{\mathrm{f}}} \operatorname{Ri} \theta, \mathbf{J}_{\mathrm{v}}=\mathrm{v} \mathbf{V}-\frac{1}{\operatorname{Re}} \frac{\mu_{\mathrm{nf}}}{\mu_{\mathrm{f}}} \frac{\rho_{\mathrm{f}}}{\rho_{\mathrm{nf}}} \operatorname{grad}(\mathrm{v})$

$\frac{\partial \theta}{\partial \tau}+\operatorname{div}\left(\mathbf{J}_{\boldsymbol{\theta}}\right)=0, \mathbf{J}_{\theta}=\theta \mathbf{V}-\frac{1}{\operatorname{Re} \cdot \operatorname{Pr}} \frac{\alpha_{\mathrm{nf}}}{\alpha_{\mathrm{f}}} \operatorname{grad}(\theta)$ 
where $\rho, \beta, \mu, \alpha$ and $\varphi$ are the density, the coefficient of thermal expansion, the dynamic viscosity, the thermal diffusivity and the nanoparticles volume fraction, respectively, taking into account subscripts f for fluid, s for solid and $\mathrm{nf}$ for nanofluid.

In Eq. (1) to (4), the space coordinates; velocities, time and pressure are normalized with the downstream channel height $\mathrm{H}$, the maximum velocity of the channel inlet $\mathrm{u}_{0}$, the characteristic time $\mathrm{H} / \mathrm{u}_{0}$ and the characteristic pressure $\rho_{\mathrm{f}} \cdot \mathrm{uo}^{2}$ respectively. The dimensionless variable $\theta$ was defined as; $\theta=\left(T-T_{c}\right) /\left(T_{h}-T_{c}\right)$ where $T_{h}$ and $T_{c}$ are hot and cold temperatures respectively. In Eq. (2) - (4), the viscosity of the nanofluid is given by Brinkman [19] as Eq. (5). The thermal diffusivity of the nanofluid is defined as Eq. (6).

$$
\begin{aligned}
& \mu_{n f}=\mu_{f} /(1-\varphi)^{2.5} \\
& \alpha_{n f}=k_{n f} /\left(\rho c_{p}\right)_{n f}
\end{aligned}
$$

where the conductivity of the nanofluid $\mathrm{k}_{\mathrm{nf}}$ is expressed as in Eq. (7) [20]. The effective density $\rho_{\mathrm{nf}}$ and the heat capacitance $\left(\rho \mathrm{c}_{\mathrm{p}}\right)_{\mathrm{nf}}$ of the nanofluid are expressed as Eq. (8) and (9) respectively [21].

$$
\begin{aligned}
& k_{n f} / k_{f}=\left[k_{s}+2 k_{f}-2 \varphi\left(k_{f}-k_{s}\right)\right] /\left[k_{s}+2 k_{f}+\varphi\left(k_{f}-k_{s}\right)\right] \\
& \rho_{n f}=(1-\varphi) \rho_{f}+\varphi \rho_{s} \\
& \left(\rho c_{p}\right)_{n f}=(1-\varphi)\left(\rho c_{p}\right)_{f}+\varphi\left(\rho c_{p}\right)_{s}
\end{aligned}
$$

The Reynolds number $R e$, the Richardson number $R i$ and the Prandtl number $P r$ are defined as in Eq. (10).

$$
R e=\rho_{f} u_{0} H / \mu_{f} \quad R i=g \beta_{f} H^{3} / v_{f}^{2} R e^{2} \quad \operatorname{Pr}=v_{f} / \alpha_{f}
$$

where $v_{\mathrm{f}}$ is the kinematic viscosity of the base fluid.

No-slip boundary conditions for velocities on all the solid walls were used. The temperature at the upper wall of the channel is constant and equal to $\mathrm{T}_{\mathrm{c}}$, corresponding to $\theta=0$. The step and the lower walls of the channel are assumed to be isothermally heated at $\mathrm{T}_{\mathrm{h}}$, corresponding to $\theta=1$.

At the channel inlet, a normal component of velocity is assumed to be zero and a fully developed parabolic profile for the axial velocity, expressed by $u(y)=-16\left(y^{2}-\right.$ $1.5 y+0.5)$, is deployed. The temperature of the incoming stream is assumed to be linear and expressed by Abu-Nada [10] $\theta(\mathrm{y})=2(1-\mathrm{y})$.

At the channel exit, the convective boundary condition, given by $\partial \phi / \partial t+u_{\mathrm{av}} \partial \phi / \partial \mathrm{x}$ $=0$, is used where the variable $\phi$ is the dependent variable $(\mathrm{u}, \mathrm{v}, \theta)$ and $\mathrm{u}_{\mathrm{av}}$ is the mean channel inlet velocity. It is noted here that, as mentioned by Sohankar et al. [22] and Abbassi et al. [23], the convective boundary condition reduces the number of iterations per time step and allows a shorter downstream computational domain when compared to the case of the Neumann boundary condition. The square obstacle is assumed to be isothermally heated at $T_{h}$, exchanging heat to the fluid flowing around it.

The instantaneous values of the drag and lift coefficients on the square obstacle were calculated at each time step. They are defined as: 


$$
\begin{aligned}
& \mathrm{Cd}=\frac{\mathrm{F}_{\mathrm{D}}}{\frac{1}{2} \rho \mathrm{u}_{0}^{2} \mathrm{~h}} \\
& \mathrm{Cl}=\frac{\mathrm{F}_{\mathrm{L}}}{\frac{1}{2} \rho \mathrm{u}_{0}^{2} \mathrm{~h}}
\end{aligned}
$$

where $F_{D}$ and $F_{L}$ are the drag and lift forces exerted by the fluid on the square obstacle, respectively. These forces are calculated by integration the viscous shear forces and pressure over the surface of the square obstacle. The thermal heat flux transferred from each face of the square obstacle to the flow is characterized by the space-averaged Nusselt number, and it is defined as the following Eq. (13).

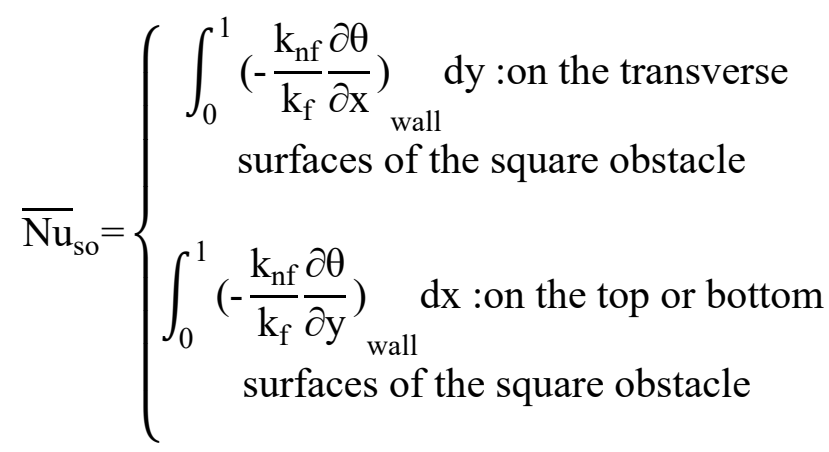

The time and space-averaged Nusselt number on each face of the square obstacle is evaluated as in Eq. (14).

$$
\langle\overline{\mathrm{Nu}}\rangle=\frac{1}{\tau_{2}-\tau_{1}} \int_{\tau_{1}}^{\tau_{2}} \overline{\mathrm{Nu}}_{\mathrm{so}} \mathrm{dt}
$$

The global time and space-averaged Nusselt number on the square obstacle is written as Eq. (15).

$$
\left\langle\overline{\mathrm{Nu}}_{\mathrm{t}}\right\rangle=\sum_{\text {all faces }}\langle\overline{\mathrm{Nu}}\rangle / 4
$$

The thermal heat flux exchanged between the flow and the horizontal walls BFS is characterized by the space averaged Nusselt number evaluated as Eq. (16),

$$
\mathrm{Nu}_{\mathrm{av}}=\frac{1}{\mathrm{~L}} \int_{0}^{\mathrm{L}} \mathrm{Nu}(\mathrm{x}) \mathrm{dx}
$$

where $N u(x)$ is the local Nusselt number, computed with the following Eq. (17) [10],

$$
\mathrm{Nu}(\mathrm{x})=\left.\frac{1}{\theta_{\mathrm{b}}(\mathrm{x})-1} \frac{\mathrm{k}_{\mathrm{nf}}}{\mathrm{k}_{\mathrm{f}}} \frac{\partial \theta}{\partial \mathrm{y}}\right|_{\text {wall }}
$$


where $\theta_{\mathrm{b}}(\mathrm{x})$ is the bulk temperature, calculated using the velocity and the temperature distribution with Eq. (18).

$$
\theta_{\mathrm{b}}(\mathrm{x})=\frac{\int_{0}^{1} \mathrm{u} \theta \mathrm{dy}}{\int_{0}^{1} \mathrm{udy}}
$$

The time and space-averaged Nusselt number at the horizontal walls BFS $\overline{\mathrm{Nu}}$ is evaluated as Eq. (19). The time interval $\left(\tau_{2}-\tau_{1}\right)$ is large compared to the period of oscillations and usually chosen as an integer multiple of period oscillations.

$$
\overline{\mathrm{Nu}}=\frac{1}{\tau_{2}-\tau_{1}} \int_{\tau_{1}}^{\tau_{2}} \mathrm{Nu}_{\mathrm{av}} \mathrm{d} \tau
$$

\section{SOLUTION PROCEDURES}

The combined continuity, momentum and energy equations are solved using a finite volume method of Patankar [24], where the control volume cells for velocity components are staggered with respect to the main control volume cells. This use of a staggered grid prevents the occurrence of checker board pressure fields. The convection terms in Eq. (2) to (4) were discretized using hybrid scheme, while the diffusion terms were discretized using second order central scheme. The SIMPLER algorithm was applied to solve the pressure-velocity coupling in conjunction with an alternating direction implicit scheme to perform the time evolution.

Our computations were achieved using $366 \times 119$ non-uniform meshes with a variable grid size of $10^{-2} \leq \Delta \mathrm{x} \leq 10^{-1}$ and $10^{-3} \leq \Delta \mathrm{y} \leq 10^{-2}$. In order to study the grid independence, one case was run with $561 \times 255$ grid points with $5.10^{-3} \leq \Delta \mathrm{x} \leq 7.10^{-2}$ and $5.10^{-4} \leq \Delta y \leq 5.10^{-3}$ for $\operatorname{Re}=450, \operatorname{Pr}=6.2, \mathrm{Ri}=0$ and $\varphi=0$ (pure water). The computation results show a difference of only $1.5 \%, 0.7 \%$ and $1.1 \%$ in the values of the reattachment length $\mathrm{Lr}$, the space averaged Nusselt numbers $\mathrm{Nu}_{\mathrm{av}}$ at the lower and the upper walls of the channel respectively. Since the computation time with $561 \times 255$ grids are nearly four times higher than that with $366 \times 119$ grids, we decided to cancel it and carry out that of the $366 \times 119$ grids. More details about the validity of the computational code used in this work are available in Bouaziz et al. [25].

\section{RESULTS AND DISCUSSION}

The effect of square obstacle on the Nusselt number at the horizontal walls of the channel is shown in Figure 2. This figure shows that the square obstacle makes a different trend for $\mathrm{Nu}$ distribution along the horizontal walls in comparison to BFS flow without square obstacle. The maximum value of $\mathrm{Nu}$ occurs at the position of the square obstacle and then it drops sharply to a low value at the reattachment point after which $N u$ approaches to a constant value far from the square obstacle.

Figure 3 depicts the variation of the time and space-averaged Nusselt number versus $\varphi$ at the horizontal walls BFS. As it can be seen, $\overline{\mathrm{Nu}}$ increases monotonously by increasing $\varphi$ for both cases, with square obstacle and without square obstacle, and still greater in with square obstacle. For both cases and in a range of $\varphi$ under consideration, 
numerical results show that $\overline{\mathrm{Nu}}$ varies linearly with respect to $\varphi$. Using the least-square method for all the computed values, the following expression of Eq. (20) to (23) were derived. These correlations have a maximum deviation of about $1.5 \%$ from the computed values.

In the lower wall:

without square obstacle, $\overline{\mathrm{Nu}}=6.88378 \varphi+2.13361$

with square obstacle, $\overline{\mathrm{Nu}}=7.66458 \varphi+2.65447$

In the upper wall:

without square obstacle, $\overline{\mathrm{Nu}}=7.71133 \varphi+2.02943$

with square obstacle, $\overline{\mathrm{Nu}}=9.06306 \varphi+2.70078$

The global time and space-averaged Nusselt number $<\overline{\mathrm{Nu}}_{\mathrm{t}}>$ over the heat transfer surface of the square obstacle is plotted against the volume fraction $\varphi$ of suspended particles over the range of $0 \%-15 \%$ in Figure 4 . Addition of nanoparticles into the base liquid enhances the thermal conduction and the enhancement increases with increasing particle concentration. This is clearly shown, which display the variation of $\left\langle\overline{\mathrm{Nu}}_{\mathrm{t}}>\right.$ over the heat transfer surface of the square obstacle with solid volume fraction. Through those results, it can be shortly concluded that the overall heat transfer from the square obstacle is greatly modified with $\varphi$. In fact, for example the exchange of heat transfer increased by $108 \%$ when $\varphi$ pass from $0 \%$ to $15 \%$.

The global time and space-averaged Nusselt number can be approximately correlated by the relationships of Eq. (24). This correlation has a maximum deviation of the order of $1.8 \%$ with the computed results.

$$
<\overline{\mathrm{Nu}}_{\mathrm{t}}>=27.747 \varphi^{2}+14.052 \varphi+6.650
$$

Figure 5 (a) shows the instantaneous streamlines for Richardson numbers $R i=1$ at $\varphi=10 \%$ without square obstacle. In the region behind the primary recirculation zone, the flow is seen to be steady where all the streamlines are found parallel. By slowly increasing the Richardson number from $\mathrm{Ri}=1$, the numerical results have shown that the onset of the first convective cell at the end of the channel at $\mathrm{Ri}=1.6$, as illustrated in Figure 5 (b). The reason of the occurrence of the convective cells may be caused by the depression zones created by the buoyancy forces once they play a major role. 


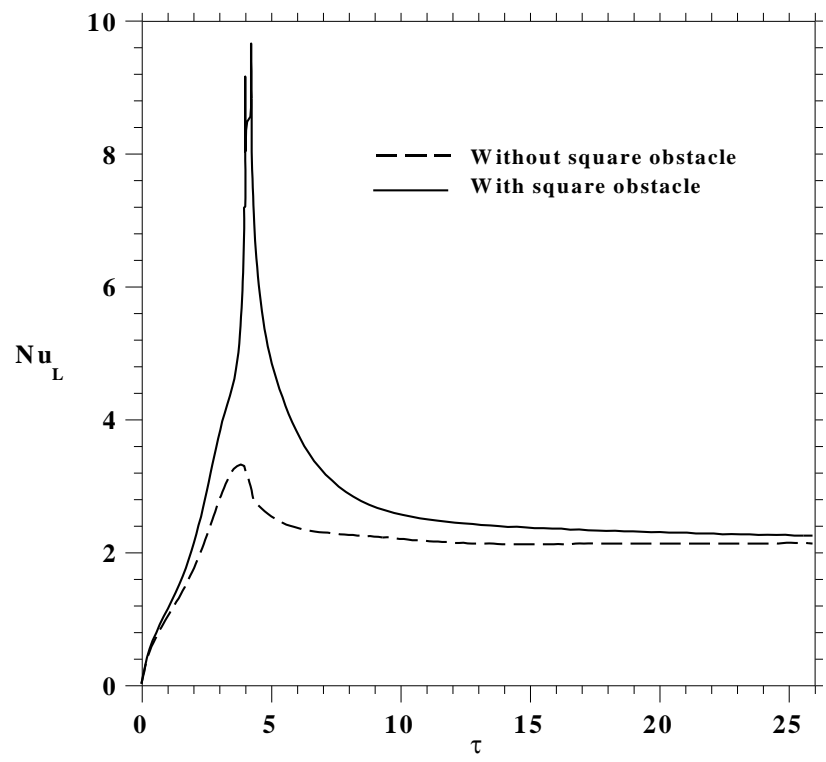

(a)

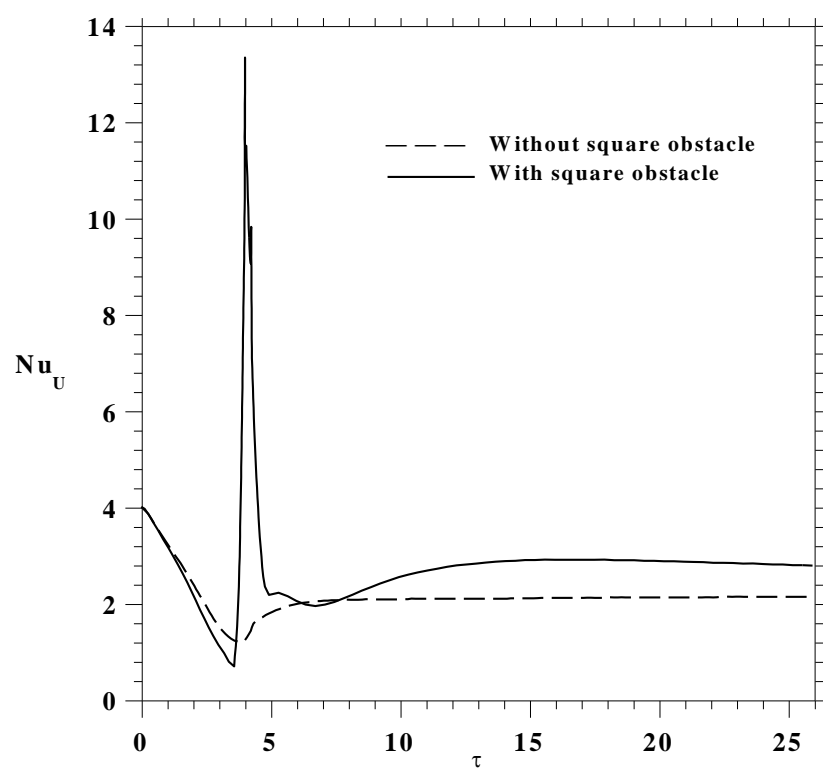

(b)

Figure 2. Effect of square obstacle on the local Nusselt distribution on the horizontal walls BFS a $\varphi=0 \%$ t and $\mathrm{Re}=450$ for (a) lower wall and; (b) upper wall. 


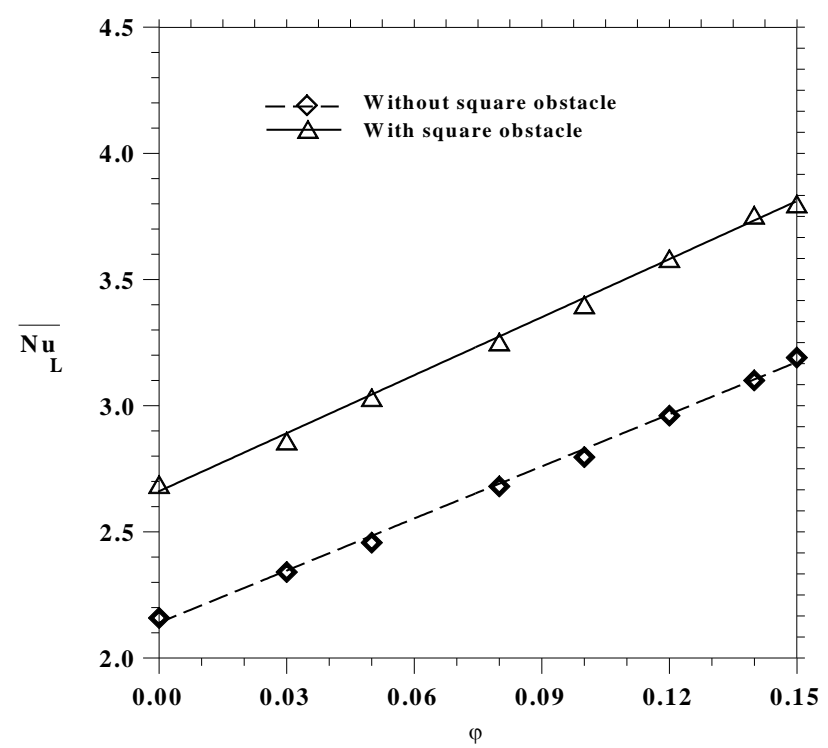

(a)

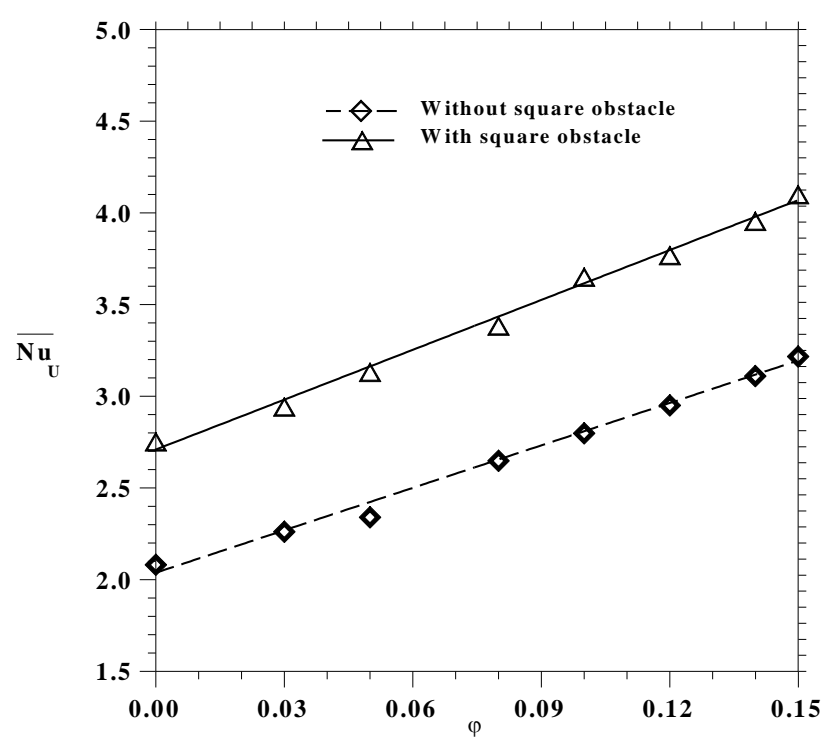

(b)

Figure 3. Effect of square obstacle on variation of the time and space-averaged Nusselt number $\overline{\mathrm{Nu}}$ on the horizontal walls BFS with volume fraction $\varphi$ for (a) lower wall and; (b) upper wall. 


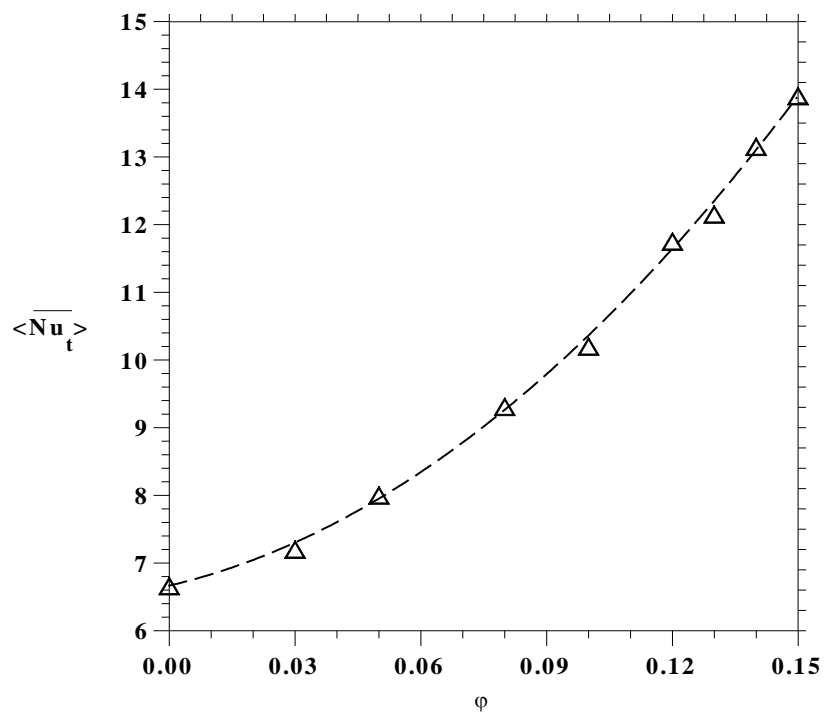

Figure 4. Variation of the global time and space-averaged Nusselt number $\left\langle\overline{\mathrm{Nu}}_{\mathrm{t}}>\right.$ on the square obstacle with $\varphi$ for $\mathrm{Ri}=0$.

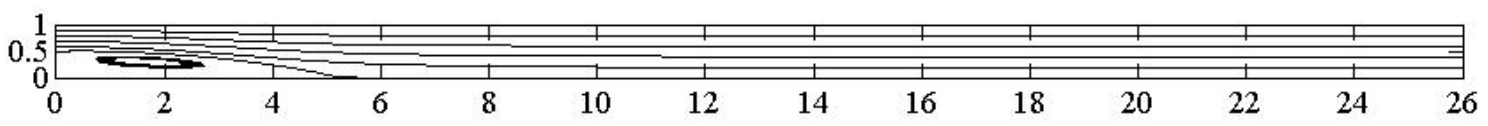

(a): $\mathrm{Ri}=1$

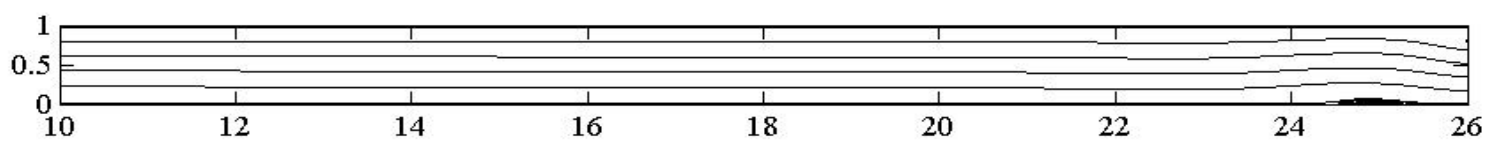

(b): $\mathrm{Ri}=1.6$

Figure 5. Flow pattern without square obstacle for two Richardson numbers at $\varphi=10 \%$

The study is limited to the flow of $\mathrm{Cu}$-water nanofluid corresponding to $\mathrm{Ri}<1.6$, where the focus is to analyze the effect of the square obstacle as well as the buoyancy forces on the heat flux exchanged between the horizontal walls and the flow. Indeed, by presenting the temporal variation of the space-averaged Nusselt number $N u_{a v}$ on the horizontal walls BFS with square obstacle, as shown in Figure 6, it is clear that the oscillatory nature of $\mathrm{Nu}_{\mathrm{av}}$ means the movement of cells near the horizontal walls. The reason may be caused by the magnitudes of the lift and drag fluctuations on the square obstacle where we have plotted in Figure 7 the temporal traces of the lift and drag coefficients at $\varphi=10 \%$ and $\mathrm{Ri}=1$.

In Figure 8 we have plotted the global time and space-averaged Nusselt number $<\overline{\mathrm{Nu}}_{\mathrm{t}}>$ over the heat transfer surface of the square obstacle against the Richardson number. As it can be seen, the heat transfer rate decreases rapidly when Ri increases until $\mathrm{Ri}=1$ and then remains constant. A decrease of $25.5 \%$ in heat transfer is observed when we pass from $\mathrm{Ri}=0$ to 1 . This is explained by the fact that when the Richardson number increases, and when the flow approaches the front face of the square obstacle, most of the 
fluids are flowing below the bottom side of the square obstacle. In the presence of nanoparticles, the effect of the buoyancy forces is found less important when Ri increases.

This can be explained by the thermophoresis forces effect. Indeed, when the nanoparticles approaching the square obstacle, they heat up and quickly move away towards the cold zone of nanofluid. These hot nanoparticles collide with cold particles and under the thermophoresis forces effect, they move toward the horizontal walls of the channel, causing therefore the migration of the nanofluid away from the square obstacle, and so enhancements in the values of the Nusselt number at the lower and the upper walls of the channel in the presence of a square obstacle. In fact, Figure 9 shows the variation of the time and space-averaged Nusselt number $\overline{\mathrm{Nu}}$ at the horizontal walls of the channel with the Richardson number. According to this figure, the flow without square obstacle, it is observed that the ranges within which buoyancy forces have a negligible effect on the heat transfer are characterized by a slight variation in $\overline{\mathrm{Nu}}$. With the square obstacle, at $\mathrm{Ri}=1.5$, the enhancements in the maximum values of the Nusselt number of $194 \%$ and $153 \%$ are obtained at the lower and the upper walls, respectively.

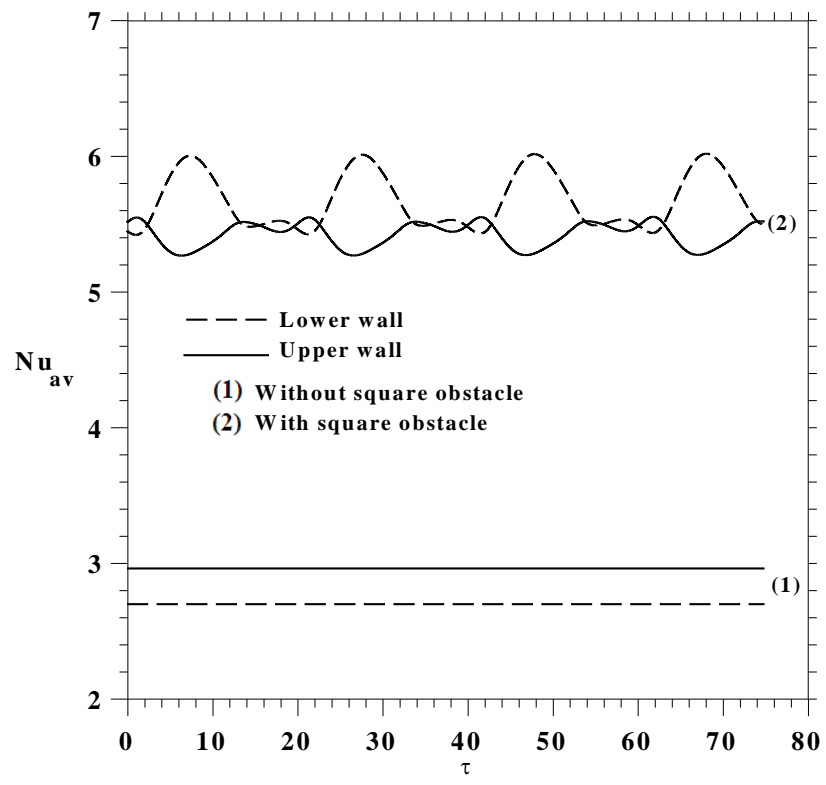

Figure 6. Effect of square obstacle on the variation of the space-averaged Nusselt number $\mathrm{Nu}_{\mathrm{av}}$ on the horizontal walls $B F S$ at $\varphi=10 \%$ and $R i=1$

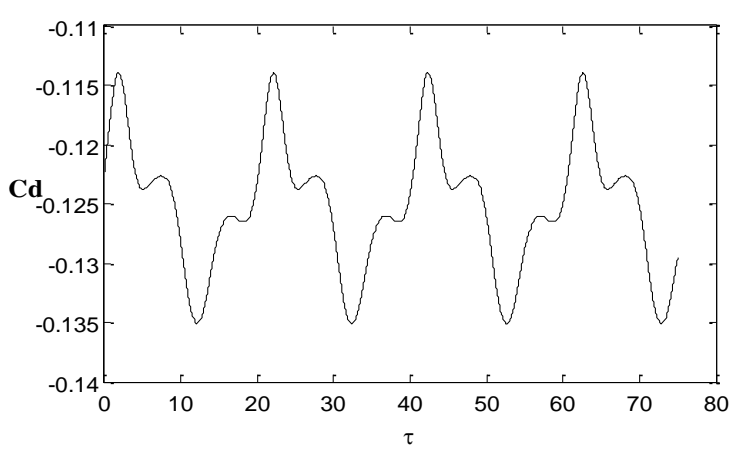

(a) drag coefficient

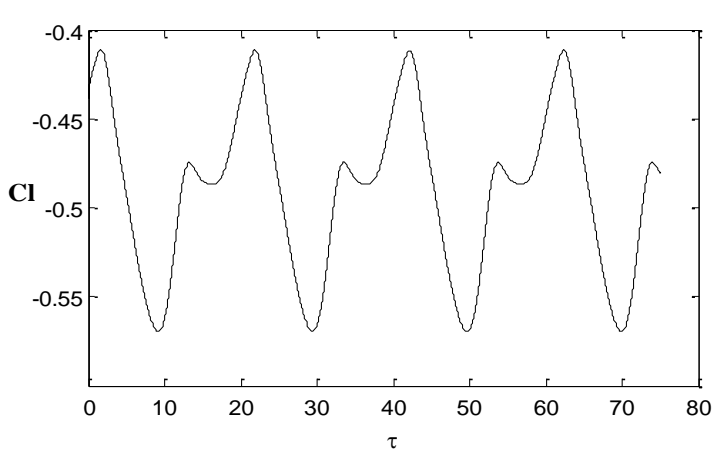

(b) lift coefficient

Figure 7. Instantaneous lift and drag coefficients a $\varphi=10 \% \mathrm{t}$ and $\mathrm{Ri}=1$ 


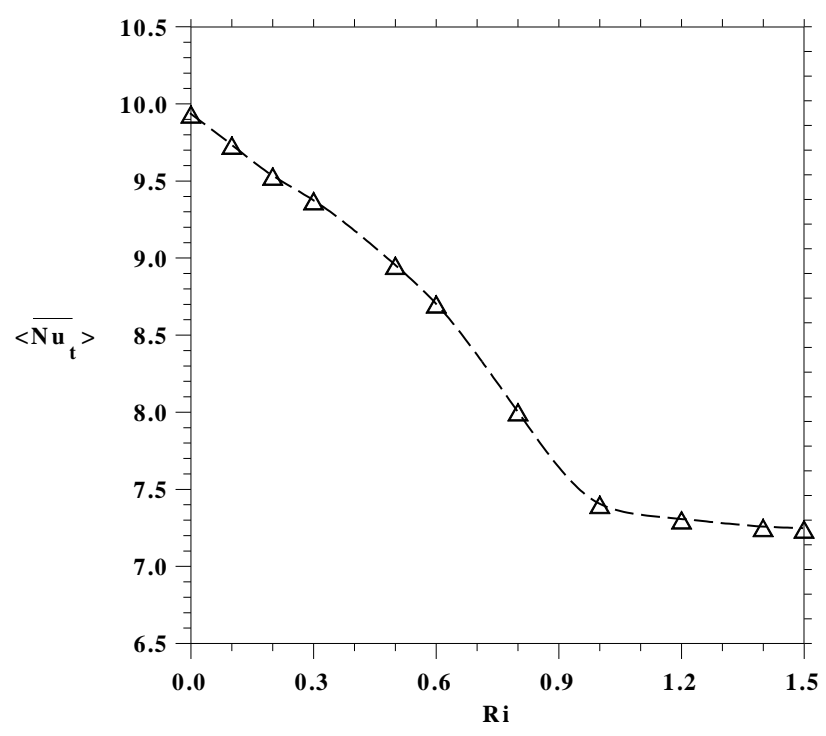

Figure 8. Variation of $\left\langle\overline{\mathrm{Nu}}_{\mathrm{t}}>\right.$ on the square obstacle with Ri for $\varphi=10 \%$

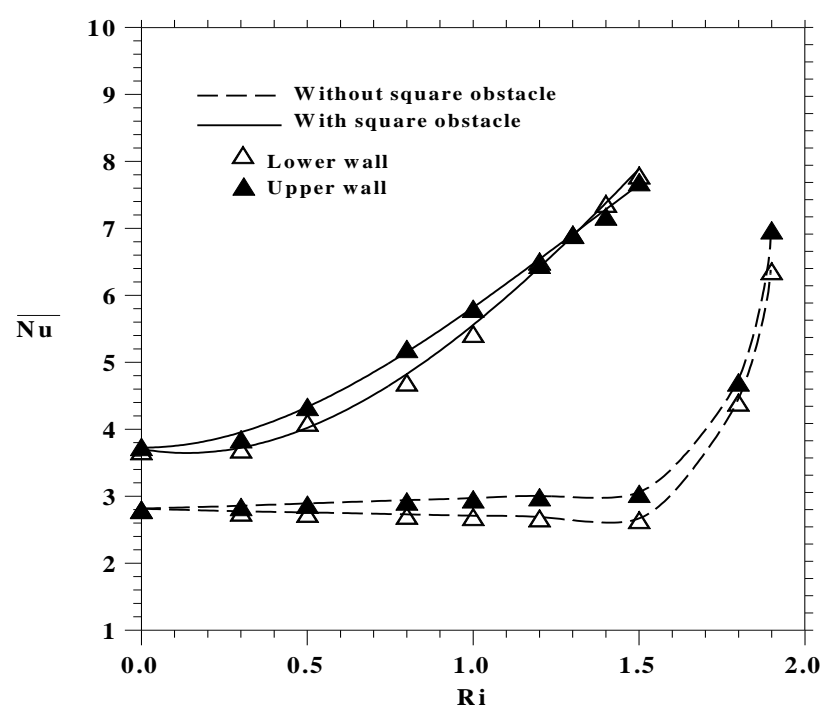

Figure 9. Effect of square obstacle on variation of $\overline{\mathrm{Nu}}$ on the horizontal walls BFS with Ri.

The computations show that the heat flux exchanged between the flow and the horizontal walls was affected by the buoyancy term when the Richardson number reaches the value characterizing the appearance of the first convective cell $\mathrm{Ri}=1.6$ for $\varphi=10 \%$. In presence of the square obstacle, a remarkable increase of $\overline{\mathrm{Nu}}$, indicating the high contribution of the buoyancy term on the increment of the heat transfer. Figure 10 (a) to (f) confirms this result where we have plotted the isotherm contours at $\varphi=0 \%$ and $\varphi=10 \%$. The effect of the square obstacle is very clear in forced convection and mixed convection. In fact, in presence of the square obstacle, the tightening of the isotherms near the horizontal walls is observed. This causes the thinning of the thermal boundary layer which tremendously increases the heat transfer rate. 


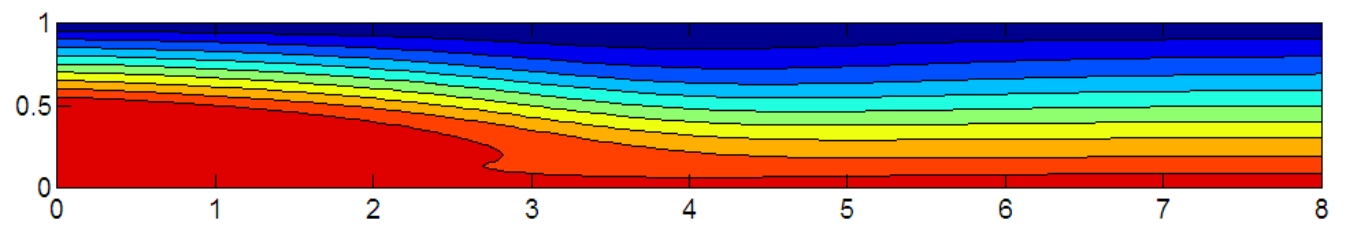

(a) Without square obstacle, $\varphi=0 \%$ and $\mathrm{Ri}=0$

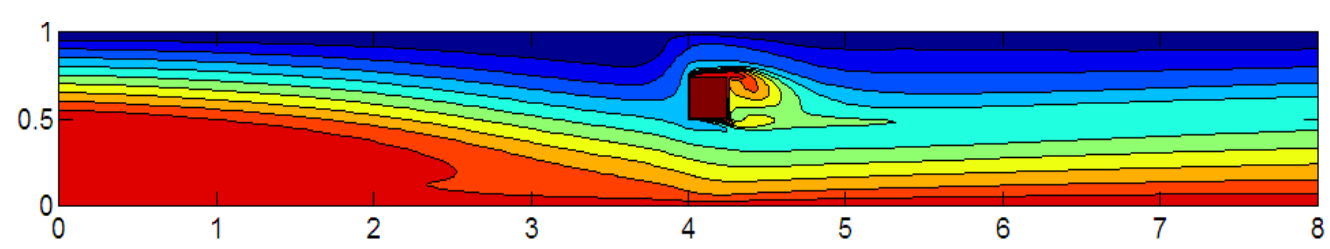

(b) With square obstacle, $\varphi=0 \%$ and $\mathrm{Ri}=0$

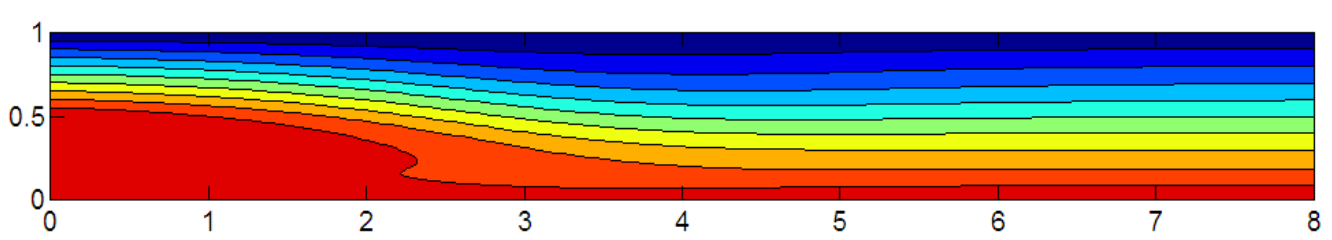

(c) Without square obstacle, $\varphi=10 \%$ and $\mathrm{Ri}=0$

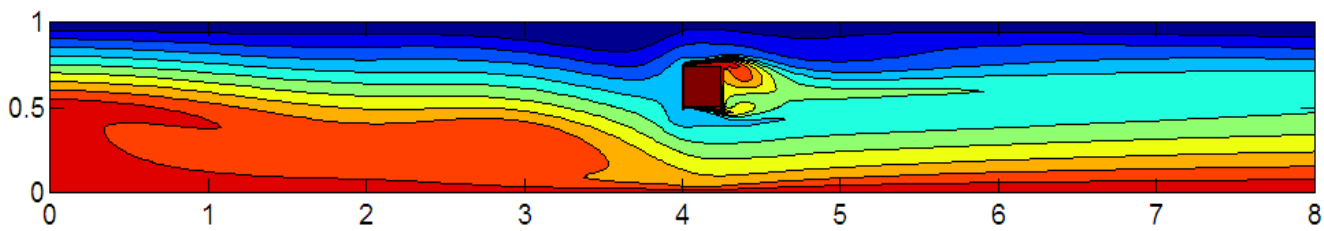

(d) With square obstacle, $\varphi=10 \%$ and $\mathrm{Ri}=0$

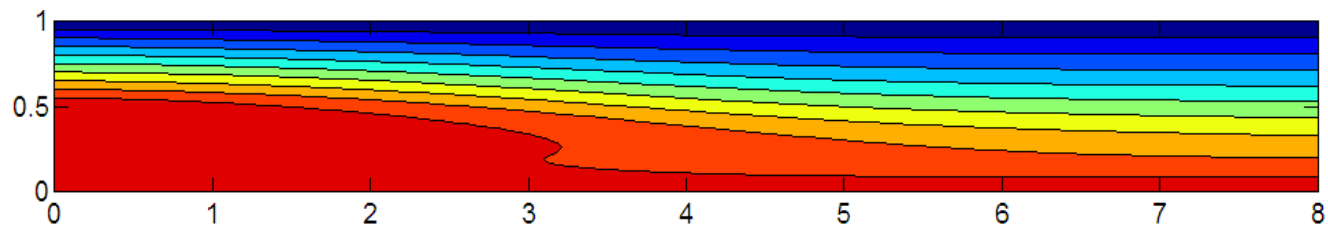

(e) Without square obstacle, $\varphi=10 \%$ and $\mathrm{Ri}=1$

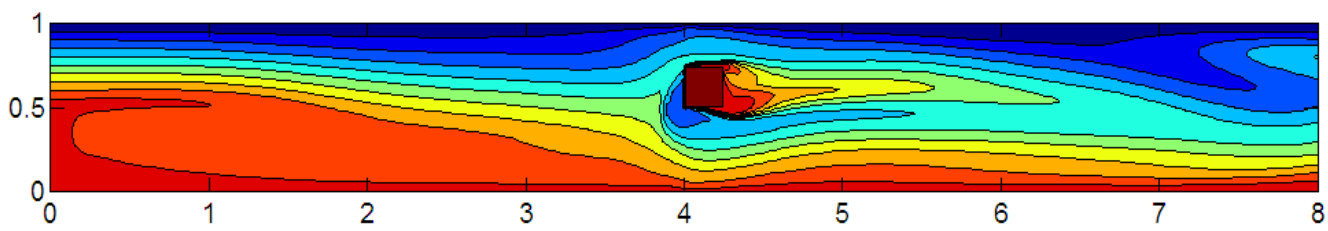

(f) With square obstacle, $\varphi=10 \%$ and $\mathrm{Ri}=1$

Figure 10. Effect of square obstacle on the isotherm contours.

\section{CONCLUSION}

Numerical study of the buoyancy effect on the flow pattern and heat transfer over a backward-facing step with a heated square obstacle using copper-water nanofluid has been performed for different nanoparticles volume fraction. For $0 \leq \mathrm{Ri} \leq 2.85$ and $0 \leq \varphi$ $\leq 15 \%$, the following conclusions can be drawn: 
a) The square obstacle plays a major role in increasing the heat transfer over a backward-facing step.

b) The time and space-averaged Nusselt number on the horizontal walls BFS $\overline{\mathrm{Nu}}$ varies linearly with respect to $\varphi$. Using the least-square method for all the computed values, the following expression may be derived: $\overline{\mathrm{Nu}}=\mathrm{a} \varphi+\mathrm{b}$, Values of the coefficient " $a$ " and " $b$ " are given by equations (20) and (21).

c) For $\varphi=10 \%$, by using square obstacle, an enhancement in the Nusselt number is registered at the horizontals wall $\mathrm{BFS}$. At $\mathrm{Ri}=1.5$, the enhancements in the maximum values of the Nusselt number of $194 \%$ and $153 \%$ are obtained at the lower and the upper walls, respectively.

d) The global time and space-averaged Nusselt number on the square obstacle can be approximately correlated by the relationship of $<\overline{\mathrm{Nu}}_{\mathrm{t}}>=14.052 \varphi+227.747 \varphi^{2}+6.650$.

\section{REFERENCES}

[1] Armaly BF, Durst F, Pereira JCF, et al. Experimental and theoretical investigation of backward-facing step flow. Journal of Fluid Mechanics 1983; 127: 473-496.

[2] K. GD. A test problem for outflow boundary conditions - flow over a backwardfacing step. International Journal for Numerical Methods in Fluids 2009; 11: 953967.

[3] Vradis, George C., Otugen, M.Volkan, Sanchez JG. Heat transfer over a backwardfacing step: solutions to a benchmark problem. In: Mechanical and Aerospace Engineering. ASME,New York, NY, United States, 1992, pp. 27-34.

[4] Barkley D, Gomes MGM, Henderson RD. Three-dimensional instability in flow over a backward-facing step. Journal of Fluid Mechanics 2002; 473: 167-190.

[5] Ramšak M, Škerget L. A subdomain boundary element method for high-Reynolds laminar flow using stream function-vorticity formulation. International Journal for Numerical Methods in Fluids 2004; 46: 815-847.

[6] Tinney CE, Ukeiley LS. A study of a 3-D double backward-facing step. Experiments in Fluids 2009; 47: 427-438.

[7] Abu-Mulaweh HI. A review of research on laminar mixed convection flow over backward- and forward-facing steps. International Journal of Thermal Sciences 2003; 42: 897-909.

[8] Bouazizi L, Turki S. Numerical simulation of flow and heat transfer of nanofluid around a heated square cylinder. Journal of Applied Fluid Mechanics 2016; 9: 1491-1501.

[9] Bouazizi L, Turki S. Numerical investigation of $\mathrm{CuO}$-water nanofluid flow and heat transfer across a heated square cylinder. International Journal of Fluid Machinery and Systems; 2016; 9 (4): 382-393.

[10] Abu-Nada E. Application of nanofluids for heat transfer enhancement of separated flows encountered in a backward facing step. International Journal of Heat and Fluid Flow 2008; 29: 242-249.

[11] Kherbeet AS, Mohammed HA, Salman BH. The effect of nanofluids flow on mixed convection heat transfer over microscale backward-facing step. International Journal of Heat and Mass Transfer 2012; 55: 5870-5881.

[12] Valipour MS, Ghadi AZ. Numerical investigation of fluid flow and heat transfer around a solid circular cylinder utilizing nanofluid. International Communications in Heat and Mass Transfer 2011; 38: 1296-1304. 
[13] Sarkar S, Ganguly S, Dalal A. Buoyancy driven flow and heat transfer of nanofluids past a square cylinder in vertically upward flow. International Journal of Heat and Mass Transfer 2013; 59: 433-450.

[14] Valipour MS, Masoodi R, Rashidi S, et al. A numerical study on convection around a square cylinder using AL2O3-H2O nanofluid. Thermal Science 2014; 18(4): 1305-1314.

[15] Nie JH, Chen YT, Hsieh HT. Effects of a baffle on separated convection flow adjacent to backward-facing step. International Journal of Thermal Sciences 2009; 48: 618-625.

[16] Bahrami A, Abdolreza S, Nassab G, et al. Effects of Baffle on Entropy Generation in Separated Convection Flow Adjacent to Inclined Backward-Facing Step. 2012; 2 (4): 53-61.

[17] Mohammed HA, Alawi OA, Wahid MA. Mixed convective nanofluid flow in a channel having backward-facing step with a baffle. Powder Technology 2015; 275: 329-343.

[18] Togun H. Laminar CuO-water nano-fluid flow and heat transfer in a backwardfacing step with and without obstacle. Applied Nanoscience 2016; 6: 371-378.

[19] Birkman HC. The viscosity of concentrated suspensions and solution. the Journal of Chemical Physics 1952; 20: 571.

[20] Khanafer K, Vafai K, Lightstone M. Buoyancy-driven heat transfer enhancement in a two-dimensional enclosure utilizing nanofluids. International Journal of Heat and Mass Transfer 2003; 46: 3639-3653.

[21] Xuan Y, Li Q. Investigation on Convective Heat Transfer and Flow Features of Nanofluids. Journal of Heat Transfer 2003; 125: 151.

[22] Sohankar A, Norberg C, Davidson L. Low-Reynolds-number flow around a square cylinder at incidence: Study of blockage, onset of vortex shedding and outlet boundary condition. 1998. Epub ahead of print 1998.

[23] Abbassi H, Turki S, Nasrallah S Ben. Channel flow past bluff-body: Outlet boundary condition, vortex shedding and effects of buoyancy. Computational Mechanics 2001; 28: 10-16.

[24] Patankar S. Numerical heat transfer and fluid flow. 1980. Epub ahead of print 1980.

[25] Bouaziz M, Bouazizi L, Turki S. Numerical study of flow and heat transfer characteristics of backward-facing step using nanofluid. UPB Scientific Bulletin, Series D: Mechanical Engineering 2017; 79(4): 123-136. 